\title{
Response of Electricity Pylon to External Loading
}

\author{
Iberahin Jusoh and Hamzah A. Ghulman \\ Mechanical Engineering Department \\ College of Engineering and Islamic Architecture \\ Umm Al-Qura University, Makkah \\ Kingdom of Saudi Arabia.
}

\begin{abstract}
External loadings on a typical transmission tower structure can be associated with several sources such as dead load, live loads, earthquake and environmental loads. The magnitude of these loads varies depending on the location, structural sizes and its design capacity. Generally, the structure was designed to withstand these loading and continue to safely serve it purpose within the anticipated design life. These loading on the pylon will induced responses within the structural elements.

In this paper, structural response due to loading on an electricity pylon was investigated. Results due to external load are presented in the form of induced member forces, stresses and related displacement. Distribution of maximum combination stresses as well as results associated with broken wires and deviation angles was also presented. Structural response due to loading from transverse wind combined with $90^{\circ}$ deviation angle results in maximum stress magnitude. The study shows that the structure is operating within it intended safe design capacity under normal loading conditions.
\end{abstract}

Keywords- Electricity Pylon, Structural Modelling, External Loading, Stress Response, Deflection, Broken Wires, Deviation Angle

\section{INTRODUCTION}

Frame structure assembled from L-section steel members fixed to the ground make a typical electricity pylon that transmits power from source to it distribution point. The wires that are supported by this pylon frame runs from adjacent pylon through to another pylon on the other side of the arrangement. The structure is designed to withstand all anticipated loads safely throughout it service life. There are several sources of loads acting on the structure mainly comes from environmental. Generally, loads on the structure are gravity load, wire pull on the tower, wind load on the conductors and earth wires as well the effect of wind on the tower itself. These loading are discussed in quite details as in [1]. Under extreme loading conditions the structure would experience maximum responses within it structural members. One of this type of loading condition is a loading under broken wire condition. Results of this study are presented in earlier publications [2], [3].

This paper focus on the general responses of a typical electricity pylon under external loading. Type of loading and it magnitude are presented. It was found that the type of loading and the structural orientation with respect to external loading and wire pull have significant effect on the study outcomes. Responses due those loading are properly highlighted in this paper.

\section{STRUCTURAL MODEL}

In this study, electricity pylon structural dimension is given in Fig.1 [4]. Basically, the structure is assembled from L-crosssection steel members to form a lattice structure supporting transmission lines. The geometrical configuration is that the base of the structure is measured at $7.064 \mathrm{~m}$ by 7.064. The frame structure at levels $18.65 \mathrm{~m} 31.81 \mathrm{~m}$ is measured at 1.820 $\mathrm{m} \times 1.820 \mathrm{~m}$. There is an inclination of about 8 degrees angle for the structural legs from ground to elevation of $18.65 \mathrm{~m}$. the purpose of this inclination is to stabilize the structure that enable it to support higher magnitude of overturning moment due to imposed loadings. There are four main horizontal bracing that supports the transmission lines at $18.65 \mathrm{~m}, 23.25$ $\mathrm{m}, 27.85 \mathrm{~m}$ and $31.81 \mathrm{~m}$ with overhanging of $3.54 \mathrm{~m}$ from the vertical members.

Finite element software is used in modeling of the structure to enable detail study and analysis be performed to yield anticipated results. In this study, sample of line element representation of structure is shown in Fig.2.

Some idealizations are made for the analysis in order to reduce the complexity of the analysis. The idealizations made are; The projected area on which the wind acts are computed by considering wind-structure interaction is one direction only. In estimating wind forces on the leeward face, a factor of 1.5 is used. The maximum wind pressure acting on the conductors and earth wires are $810 \mathrm{~N} / \mathrm{m}^{2}$ and $430 \mathrm{~N} / \mathrm{m}^{2}$ respectively.

\section{LOADING AND FORMULATION}

Loading on electricity pylon comes from several sources namely; wind load, dead load, tensional pull in conductors and earth wires and vertical load. Wind force is found to be the most dominant of all those forces [5]. An electricity pylon has to withstand the loadings ranging from straight runs up to varying angles and dead ends. They are design to withstand load due to variation of angles in the line in addition to the wind and broken conductor loads.

Force due to wind interaction with structural members is estimated using the following relationship;

$$
F_{w}=\frac{1}{2} \rho v^{2} A
$$

where $\rho$ is density of air, $v$ is wind velocity and $A$ is surface area of the structure. 


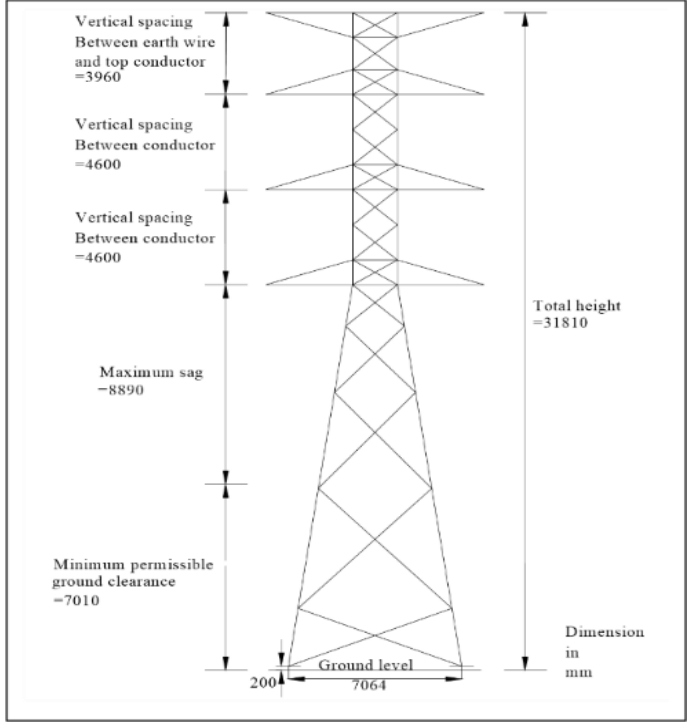

Fig. 1. Typical configuration of electricity pylon [4].

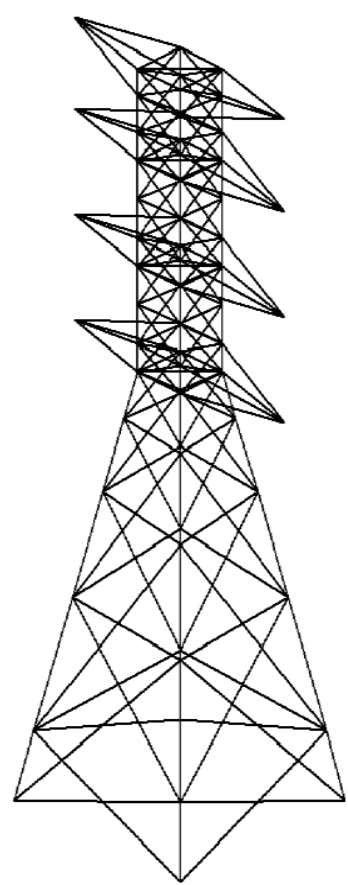

Fig. 2. Computer model of Electricity Pylon

However, in practice wind-structure interaction creates more complex forces due to drag, vortex induced displacement as well as shielding effect. Generally, the higher the wind speed the higher the wind force exerted on the structure. Wind speed patterns can be depicted as a wind speed spectrum. A high value indicates a significant change in wind speed over the corresponding time period, typically as shown in Fig.3. [6]. The peaks in the wind speed spectrum account for annual, seasonal and daily patterns as well as short-term turbulences.

A striking phenomenon is the spectral gap between time periods of 10 minutes to 2 hours. The distribution of hourly average wind speed is described by Weibull distribution;

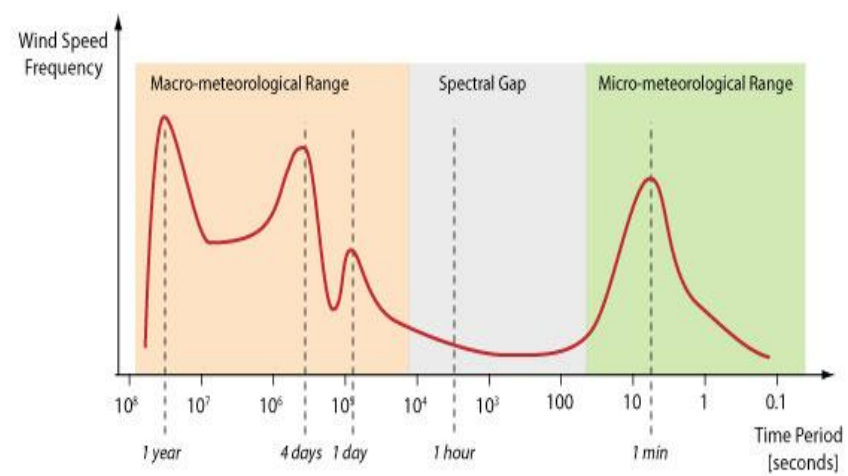

Fig.3. Wind speed distribution patterns [6]

$$
h\left(v_{i}\right)=\frac{k}{B}\left(\frac{v}{B}\right)^{k-1} \exp \left[-\left(\frac{v}{B}\right)^{k}\right]
$$

with shape factor $k$ and scaling factor $B$ which roughly 125 percent of the average annual wind speed.

Wind intensity is lower at ground level, $H_{G}$ due to turbulent developed in view of friction with the rough ground surfaces. Then as the height increases the effects of surface reduced and becomes negligible at higher level where the air flows freely under the influence of pressure gradient. Variation of wind speed $v_{G}$ to height from the ground varies according to power law as follows.

$$
v_{H}=v_{G}\left(\frac{H}{H_{G}}\right)^{\frac{1}{7}}
$$

where $v_{H}$ is the wind speed at $\mathrm{H} \mathrm{m}$ above the ground.

Another significant characteristic of this external load is its directionality that will affects the response of the overall stresses within the structural members. Basic wind directions as refer to one structure are transverse and longitudinal directions as discussed in previous publications [1], [2]. It was found that wind acts in $45^{\circ}$ direction gives maximum loading and response onto the structure, thus this angle is considered as a critical loading angle for the structure.

The strains and displacements of stressed material are small for structural members under tension. However, structural member subjected to compression, there may develop relatively large deformations in particular when the structure is under transverse cables pulling load as shown in Fig.12, Results from previous study shows that the structural member of electricity pylon usually experiences maximum high stress during the breaking of transmission lines attached to the structure [2].

The dead load of the structure will depend on the bracing arrangement, strut formula used and the quality and quantities of steel used [7]. The tension in the conductors and earth wires result from deviation of line due to the force being applied to the transmission lines.

Primary wind-structure interaction considered in this study is illustrated in Fig.4. It is in the transverse orientation and the in-line direction to structural geometry plan. Other incidental wind direction is between $0^{\circ}$ to $90^{\circ}$ angle, i.e., between in-line to transverse. 


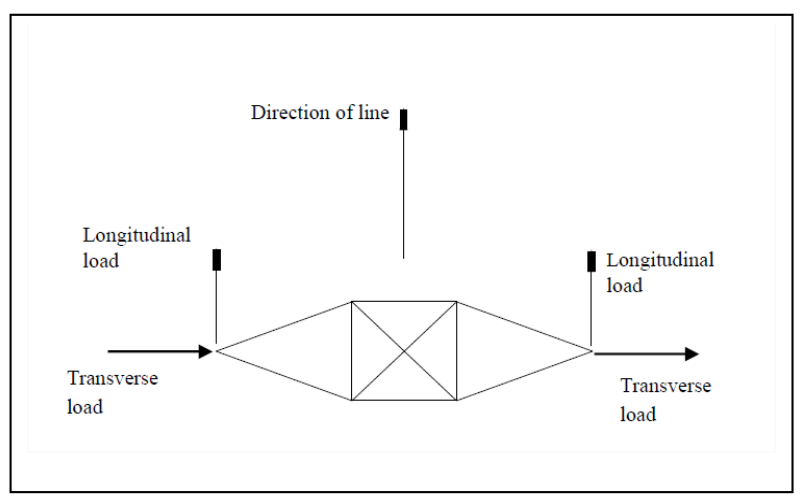

Fig.4. Plan view of directional loads (Transverse and Longitudinal)

Structural response to external loading also very much influences by the angle of wire pulls between the electricity pylons. This angle of wire pull is illustrated in Fig.5 as a deviation angle. Results shows that the variation in this angle give rise to a significant variation in stress response within the structural members as presented later in section V.

\section{METHOD OF ANALYSIS}

In simulation study, details of pylon structure were selected as input modelling stage follows with related parameters such as type of loading and it associated magnitude, wire pull directions, element sizes and material properties. Static consideration of structural analysis is adopted in this study and it is sufficient to determine the loading effects on the electricity pylon [3]. For the majority of towers, this analysis of the structure under the factored loads is sufficient to determine the loading effects [7]. Several conditions of external loading were investigated. The environmental loads considered in design can be assumed static or idealized steady wind (quasi-static). In certain cases, there are needs for dynamic analysis such as in the case of accidental loads that usually related with broken wires condition that produces shock loads.

Stress calculations in structural members are normally obtained from a linear elastic analysis where members are assumed to be axially loaded. Results from full scale tower tests often indicate that bending stresses in the members could be as high as axial stresses when compared data from fullscale tests and with predicted results using current techniques. However, test results are only valid for the particular tower under the particular test loading conditions, and they may not predict exactly how a tower may behave in practice under different loading conditions [8].

The structural response under wind action can be assumed to be stationary Gaussian process [9]. In this case the probability density function is;

$$
F\left(\eta_{e}\right)=\exp \left[-v T \exp \left(-\frac{\eta_{e}^{2}}{2 \sigma^{2}}\right)\right]
$$

and the mean, $\bar{\eta}_{e}$ and standards deviation, $\sigma \eta_{e}$ of the extreme values are given as follows;

$$
\bar{\eta}_{e} \cong(2 \ln v T)^{0.5} \sigma+\frac{0.5772 \sigma}{(2 \ln v T)^{0.5}}
$$

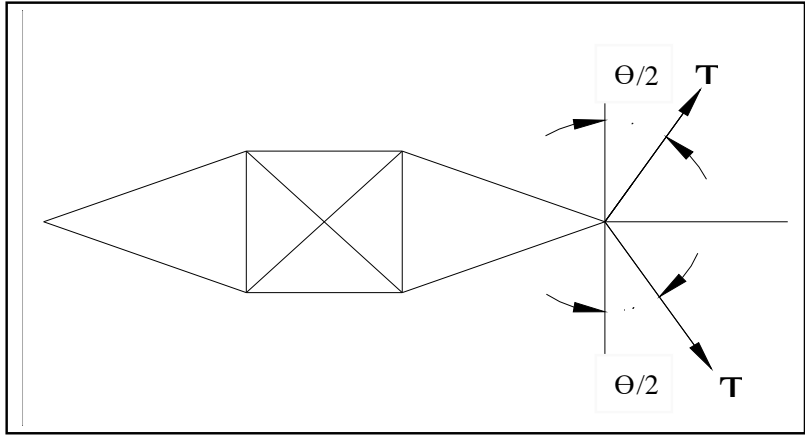

Fig.5. Wire line deviation angle.

$$
\sigma \eta_{e}=\frac{\pi \sigma}{\sqrt{6}(2 \ln v T)^{0.5}}
$$

where $v$ is the zero-crossing frequency, $T$ is the duration, $\sigma$ is the standard deviation of the sample and $\gamma=0.5772$ is the Euler's constant.

\section{RESULTS AND DISCUSSION}

Structural response to external loading was investigated with some outcome presented here in addition to earlier results that been published [1], [2], [3].

Magnitude of maximum wind load due to wind-structure interaction for three different directions namely transverse, longitudinal and $45^{\circ}$ incidence angle are presented in Table 1 and illustrated in Fig. 6. Results also shows structural response in term of stresses and displacement. The maximum value of the total applied force which is $24.9 \mathrm{kN}$.

Fig. 6 shows the structural response due to transverse loading, longitudinal loading and with wind-structure incident angle of $45^{\circ}$. Transverse wind produce higher stress and displacement response as compared to longitudinal wind loading. However, the wind loading at $45^{\circ}$ incident angle induced highest stress response and significant structural displacement. On the reason that can be explained to reached to this result is the fact that orientation of structure and the effective cross-sectional area of the structure are at a maximum at $45^{\circ}$ wind interaction. In relation to vertical bar chart in Fig. 6, structural stress responses to wind loading in three directions of wind-structure interaction namely, transverse, inline as well at $45^{\circ}$ are presented in Fig.7, Fig.8 and Fig.9.

Example of loading tree in relation to transverse wind direction acting on the structure is illustrated in Fig.10. The detail shows loading magnitude in horizontal and vertical directions experienced by elements within the structure. Maximum horizontal load found to $70.336 \mathrm{kN}$.

TABLE 1. Response comparison due to wind loading conditions.

\begin{tabular}{|c|c|c|c|}
\hline Condition & $\begin{array}{c}\text { Force } \\
F_{\max }(\mathrm{kN})\end{array}$ & $\begin{array}{c}\text { Displacement } \\
\square \max (\mathrm{mm})\end{array}$ & $\begin{array}{c}\text { Stress } \\
\square \max (\mathrm{MPa})\end{array}$ \\
\hline Base case & 21.9 & 92.92 & 167.95 \\
\hline Transverse wind & 24.9 & 107.72 & 124.19 \\
\hline Longitudinal wind & 19.0 & 45.81 & 106.56 \\
\hline $45^{\circ}$ wind & 21.9 & 92.92 & 167.95 \\
\hline
\end{tabular}




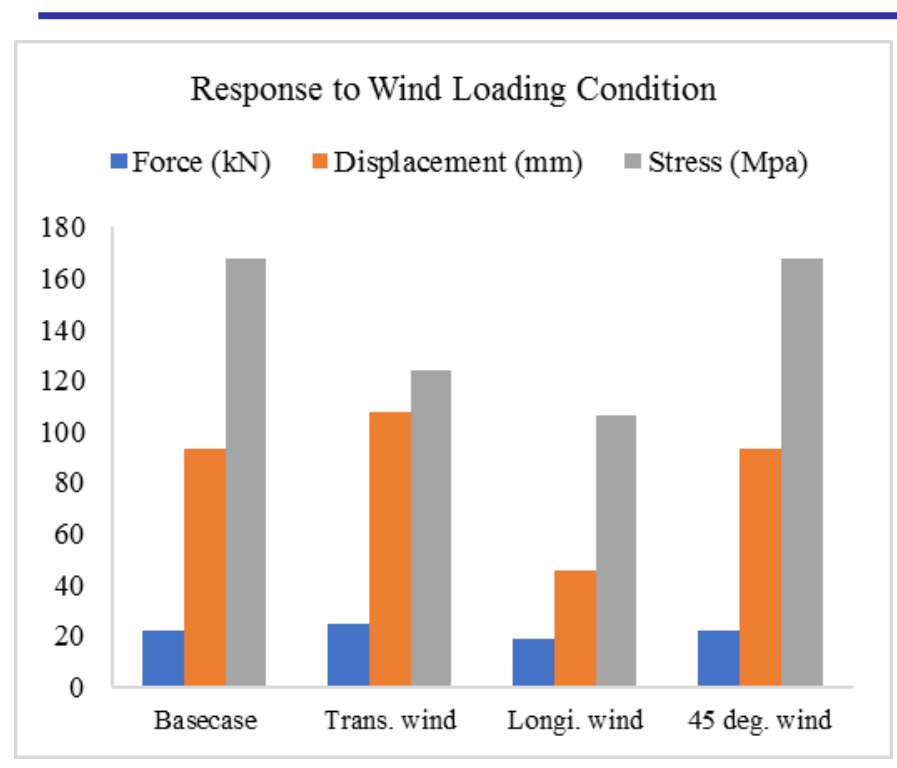

Fig.6; Structural response to wind loading condition.

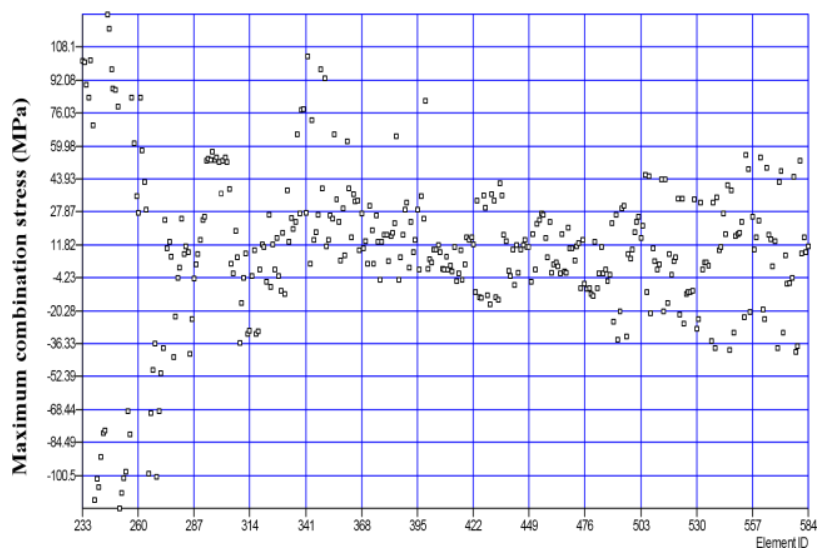

Fig. 7. Maximum combination stress for wind load in transverse direction.

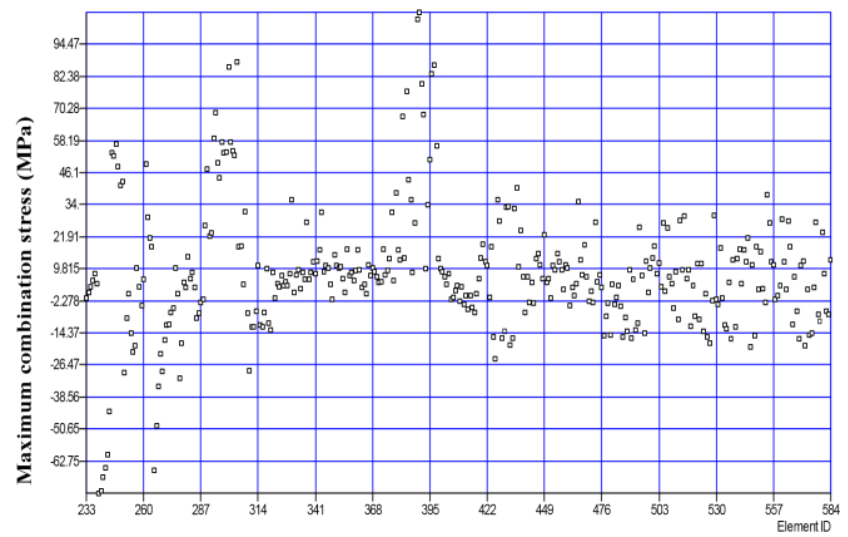

Fig. 8. Maximum combination stress for wind load in longitudinal direction.

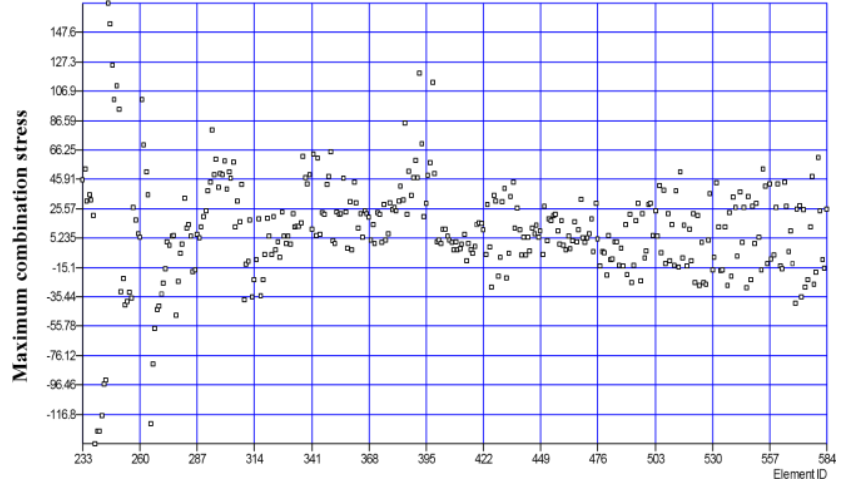

Fig. 9. Maximum combination stress for wind load in $45^{\circ}$.

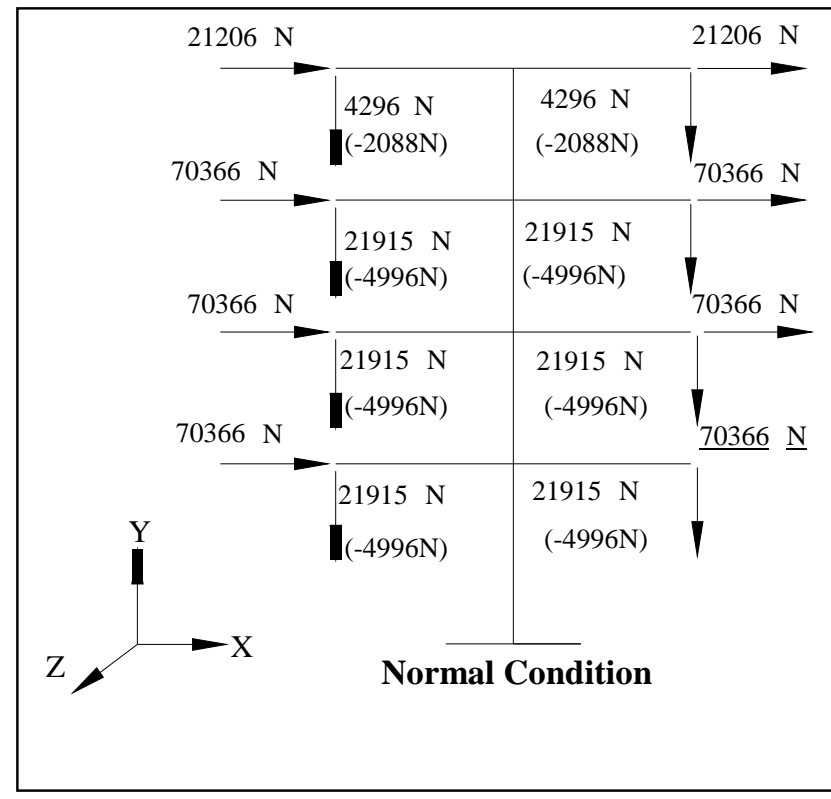

Fig. 10: Structural loading tree for $90^{\circ}$ deviation angle (Transverse wind load)

Response of structure with broken wire conditions expected to experience higher loading especially shock loads. Broken wire condition results in the instant imbalance of pull within the structural frame that see higher stress responses in the structural element. Table 2 shows the maximum applied loads on the structure occur when middle and bottom conductor broken and also top and middle conductor broken which is $43.3 \mathrm{kN}$. It was found that maximum displacement within the structure is $124.27 \mathrm{~mm}$ and exerted on node 618 . Details consideration of this aspect of loading and responses was previously discussed [2]. Related maximum stress response due to broken wires gives rise to some structural members experiences compressive loads. The maximum absolute stress magnitude is $211.49 \mathrm{MPa}$ occurs when the top and middle conductors are broken as shown in Fig.11. The Figure also presents related maximum magnitude of force and deflection. It was found out that maximum stresses occurred when the top and middle conductors are broken with absolute stress of $211.49 \mathrm{MPa}$. 
TABLE 2. Structural response due to broken wires.

\begin{tabular}{|c|c|c|c|}
\hline Condition & $\begin{array}{c}\text { Force } \\
\mathrm{F}_{\max }(\mathrm{kN})\end{array}$ & $\begin{array}{c}\text { Displacement } \\
\square_{\max }(\mathrm{mm})\end{array}$ & $\begin{array}{c}\text { Stress } \\
\square_{\max }(\mathrm{MPa})\end{array}$ \\
\hline Base case & 21.9 & 92.92 & 167.95 \\
\hline Broken earth wire & 21.9 & 88.13 & -173.12 \\
\hline $\begin{array}{c}\text { Broken top \& } \\
\text { middle conductors }\end{array}$ & 43.3 & 124.27 & -211.49 \\
\hline $\begin{array}{c}\text { Broken middle \& } \\
\text { bottom conductors }\end{array}$ & 43.3 & 90.78 & -209.61 \\
\hline
\end{tabular}

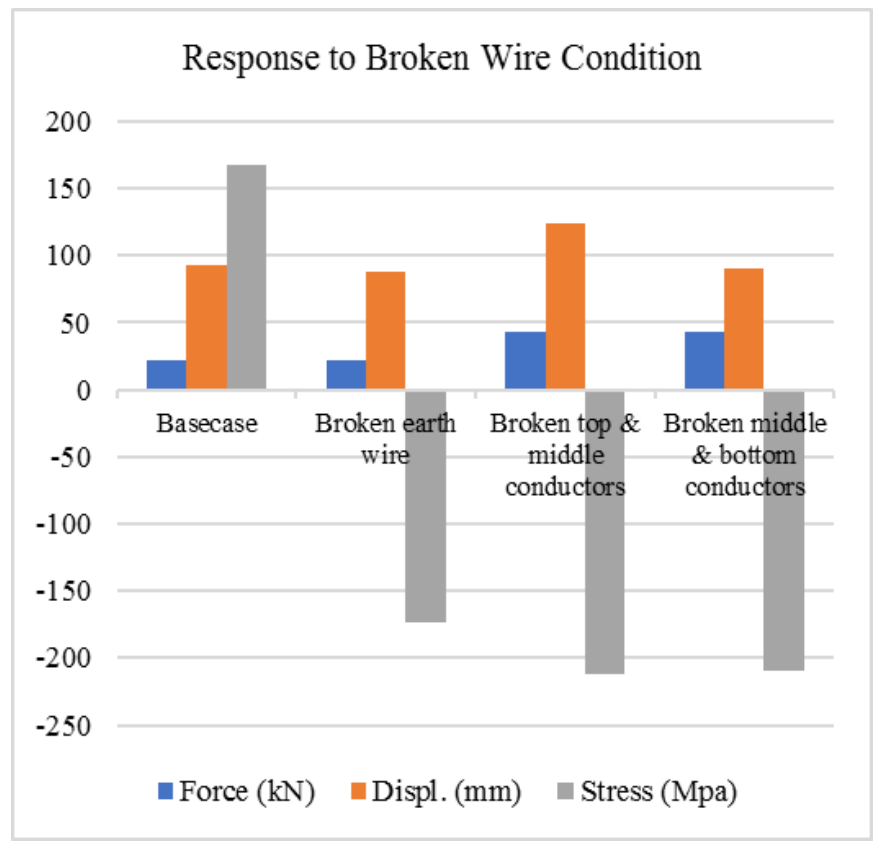

Fig.11. Structural response to broken wire condition.

Since the force acting on the tower structure is combination of force from different direction, total translation is chosen because it represents combination displacement on three different directions. Total translation is the summation of displacement in 3 axes representing total displacement of each node from its origin location. Total force, translational displacement and element stresses for wind load in relation to deviation angles are presented in Table 3 and illustrated in Fig. 12 and Fig.13. The results clearly show that maximum combination of forces, displacements and stresses occurred when deviation angle is $90^{\circ}$ to the plan geometry of the structure that is in transverse direction. Maximum combination force is $73.7 \mathrm{kN}$, maximum deflection is $384.98 \mathrm{~mm}$ and maximum stress is $424.86 \mathrm{MPa}$.

TABLE 3. Structural response to variation in deviation angle.

\begin{tabular}{|c|c|c|c|}
\hline $\begin{array}{c}\text { Deviation Angle } \\
(\text { degree })\end{array}$ & $\begin{array}{c}\text { Force } \\
\mathrm{F}_{\max }(\mathrm{kN})\end{array}$ & $\begin{array}{c}\text { Displacement } \\
\square_{\max }(\mathrm{mm})\end{array}$ & $\begin{array}{c}\text { Stress } \\
\square \max \end{array}$ \\
\hline 2 & 14.1 & 67.97 & 105.15 \\
\hline 10 & 24.5 & 102.72 & 124.19 \\
\hline 30 & 36.7 & 180.87 & 200.29 \\
\hline 60 & 56.2 & 290.68 & 316.98 \\
\hline 90 & 73.7 & 384.98 & 424.86 \\
\hline
\end{tabular}

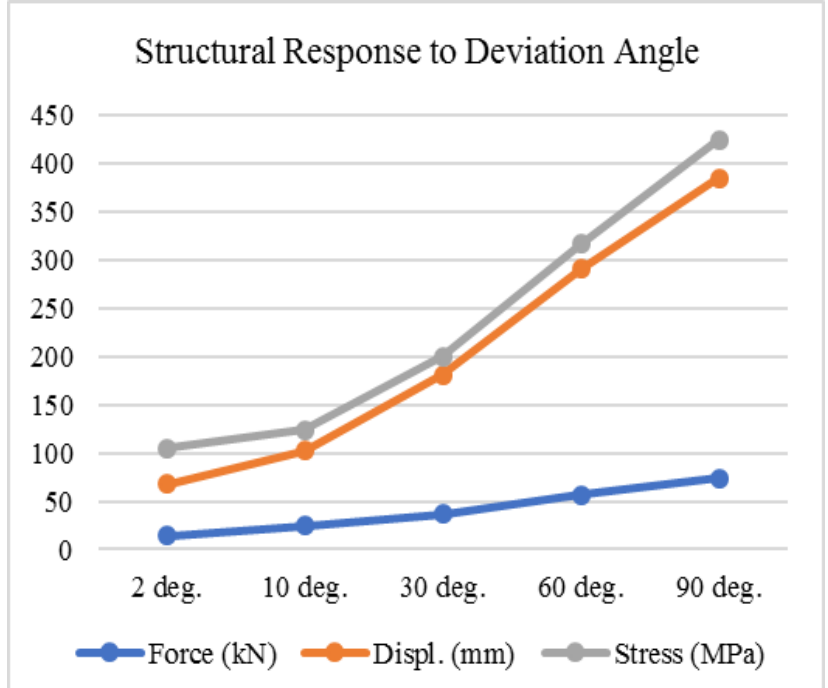

Fig.12. Structural response to variation in deviation angle.

Total displacement versus height from ground level

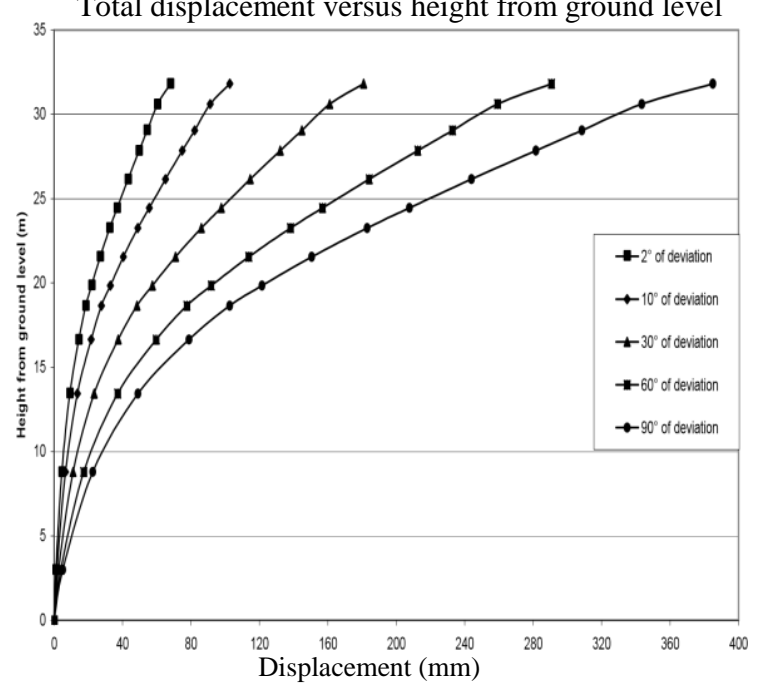

Fig. 13. Structural displacement refer to angle of deviation.

\section{CONCLUSSIONS}

Response of electricity pylon to external loading was investigated. Generally, the following conclusions may be drawn;

1. Several types of loading exerted on to electricity pylon during it service life.

2. Structural response due wind-structure interaction in term of force, displacement and stress are $24.7 \mathrm{kN}, 107.72 \mathrm{~mm}$ and $124 \mathrm{MPa}$ respectively.

3. Broken wire condition gives rise to significant response within the structure with maximum absolute stress within the element of 211.49 MPa.

4. Electricity pylon experience maximum response (force, displacement and stress) due to combination of wind loading and deviation angle in wire pull between pylon.

5. Maximum combination structural responses for force, displacement and stress are $73.7 \mathrm{kN}, 384.98 \mathrm{~mm}$ and 424.86 MPa respectively.

6. Appropriate allowances and factors of safety must be considered at the design stage of the structure. 


\section{REFERENCES}

[1]. Jusoh, I., Ghulman, H. A., Mandourah, T.S. and Tan,C. C., "Loading Analysis of a Typical Electricity Pylon", Intl Jour of Eng Res and Management, Vol. 4(10), 2017.

[2]. Jusoh, I., "Electricity Pylon with Broken Wires Condition", Intl Jour of Eng Res and Tech, Vol.6(12), 2017.

[3]. Jusoh, I., "Highly Stressed Elements on Electricity Pylon under Typical Loading Conditions", Intl Jour of Eng Res and Tech, Vol.7(3), 2018.

[4]. TNB Transmission, "Technical Specification of TNB Transmission Network Sdn Bhd." TNB Transmission: Petaling Jaya, Malaysia (2004).
[5]. Murthy, S.S. (1990). “Transmission Line Structures.” Singapore: McGraw Hill Inc.

[6]. www.greenrhinoenergy.com (access Mac 2018).

[7]. BS8100 (1986). "Lattice Tower and Mast, Part 1. Code of Practice for Loading." British Standard Institution, London.

[8]. Roy, S., Fang, S. and Rossow, E., "Secondary Stresses on Transmission Tower Structures." Journal of Energy Engineering, ASCE 1102 (1984): 157-172.

[9]. Battista, R.C. and Rodrigues, R.S., "Dynamic Behavior and Stability of Transmission Line Towers under Wind Forces." Journal of Wind Engineering and Industrial Aerodynamics (2003): 1051-1067 